\title{
A Dynamic Emergency Decision-Making Method Based on Group Decision Making with Uncertainty Information
}

\author{
Jing Zheng ${ }^{1,2} \cdot$ Yingming Wang ${ }^{2,3} \cdot$ Kai Zhang ${ }^{4} \cdot$ Juan Liang $^{5}$
}

Accepted: 8 September 2020/Published online: 8 October 2020

(C) The Author(s) 2020

\begin{abstract}
In emergency decision making (EDM), it is necessary to generate an effective alternative quickly. Case-based reasoning (CBR) has been applied to EDM; however, choosing the most suitable case from a set of similar cases after case retrieval remains challenging. This study proposes a dynamic method based on case retrieval and group decision making (GDM), called dynamic casebased reasoning group decision making (CBRGDM), for emergency alternative generation. In the proposed method, first, similar historical cases are identified through case similarity measurement. Then, evaluation information provided by group decision makers for similar cases is aggregated based on regret theory, and comprehensive perceived utilities for the similar cases are obtained. Finally, the most suitable historical case is obtained from the case similarities and the comprehensive perceived utilities for similar historical cases. The method is then applied to an example of a gas explosion in a coal company in China. The results show that the proposed method is feasible and effective in EDM. The advantages of the
\end{abstract}

Jing Zheng

zhengjing80@qq.com

1 College of Electronics and Information Science, Fujian Jiangxia University, Fuzhou 350108, China

2 Institute of Decision Science, Fuzhou University, Fuzhou 350116, China

3 Key Laboratory of Spatial Data Mining and Information Sharing of Ministry of Education, Fuzhou University, Fuzhou 350116, China

4 Department of Information Engineering, Fujian Chuanzheng Communications College, Fuzhou 350007, China

5 College of Business Administration, Fujian Jiangxia University, Fuzhou 350108, China proposed method are verified based on comparisons with existing methods. In particular, dynamic CBRGDM can adjust the emergency alternative according to changing emergencies. The results of application of dynamic CBRGDM to a gas explosion and comparison with existing methods verify its feasibility and practicability.

Keywords Case-based reasoning - Dynamic emergency decision making · Group decision making - Intervalvalued Pythagorean fuzzy linguistic variable $($ IVPFLV) · Regret theory

\section{Introduction}

In recent years, several major emergency events have occurred, including the Indian Ocean Tsunami in 2004, the 12 May Wenchuan Earthquake in China in 2008, the missing Malaysian Airlines MH370 in 2014, and the fire in Rio de Janeiro, Brazil, in 2018. These disasters not only disrupted daily life, but also caused huge loss of property and lives. Moreover, the environment is affected, and secondary derivative hazards arise. Consequently, emergency decision making (EDM) has been garnering increasing attention from both national governments and scholars (Ding et al. 2019; Li and Cao 2019; Zheng et al. 2019). To reduce or eliminate all types of losses due to emergency events, an effective emergency alternative needs to be formulated in a short period (Peng and Garg 2018). However, because by nature emergency events occur suddenly and decision information contains uncertainty, emergency plans may fail, and it is difficult to deal with such events using conventional decision-making methods. 
To overcome the issues identified above, case-based reasoning (CBR), which is an artificial intelligence method, is widely applied in emergency response. For example, Yu et al. (2018) applied CBR to risk response for an urban water supply network, Fan et al. (2015) used CBR to generate project risk response strategies, and Liao et al. (2012) applied CBR to design an environmental emergency preparedness system. These methods employ the alternative of the most similar historical case as the alternative of the target case. However, in scenarios where the most similar historical case is not the most appropriate for the target case, the decision-making result is affected negatively. Therefore, it is necessary to develop a method by which the most suitable historical case can be selected from a similar case set.

Selection problems in EDM are often solved using group decision making (GDM). For example, $\mathrm{Xu}$ et al. (2019) proposed a large-group emergency risk decision method based on data mining of public attribute preference, to select the most suitable alternative from three alternatives. Ding and Liu (2019a) developed an integrated approach based on prospect theory and VIKOR (Vise Kriterijumska Optimizacija i Kompromisno Resenje) to solve EDM problems. Ding and Liu (2019b) presented a novel combined approach by extending the zero-sum game using the best-worst method and Pythagorean fuzzy uncertain linguistic variables. Yu et al. (2011) proposed a distance-based GDM method to select the most suitable alternative from five alternatives, to manage a chemical spill emergency. Wang et al. (2017) developed a GDM based on prospect theory to select the most suitable alternative from four alternatives for a barrier lake emergency. Ding et al. (2020) presented an EDM approach based on picture fuzzy sets and axiomatic design technique, to determine an optimal rescue plan. The above studies used crisp numbers, interval numbers, and linguistic variables to express the evaluation information. In EDM, the decision situation is uncertain, and the decision information is inaccurate; however, effectively expressing the information is important (Wan et al. 2017).

Due to the dynamic and uncertain characteristics of emergencies, scholars often adopt fuzzy theory when studying EDM (Jiang et al. 2008; Fan et al. 2014; Wang et al. 2018; Ding et al. 2019; Ding and Liu 2019a; Ding and Liu 2019b; Gao et al. 2019; Zheng et al. 2019). In particular, linguistic variables and Pythagorean fuzzy sets have been widely used in the expression of the opinions of decision makers (Zadeh et al. 1975; Wu et al. 2018; Wang and Li 2020). Recently, Du et al. (2017) proposed a new linguistic variable called interval-valued Pythagorean fuzzy linguistic variable (IVPFLV), which combines Pythagorean uncertain linguistic sets and interval-valued Pythagorean fuzzy sets. The membership degree and non- membership degree of an IVPFLV is an interval value in the range $[0,1]$. They can describe the evaluation of decision makers more accurately, when expressing the opinions of decision makers as precise numbers is difficult. Furthermore, several studies (Ding et al. 2019; Liu et al. 2019) have applied IVPFLVs to handle information given by decision makers in EDM with some success. Hence, IVPFLVs are suitable for situations wherein information is given by decision makers.

The purpose of GDM is to make the best decision based on the opinions of several experts. Most GDM methods assume that decision makers are completely rational. In realistic situations, decision makers often exhibit bounded rationality under risk and uncertainty. The prospect theory has been used to describe the psychological behavior of a decision maker (Ren et al. 2017; Wang et al. 2017; Dou et al. 2018; Zhang et al. 2018; Gao et al. 2019). However, there are certain limitations for instance, the aspiration levels of the attributes are required, which is difficult because they must be determined in advance. To avoid this problem, the regret theory has been used to express the psychological behavior of decision makers. The regret theory, introduced by Bell (1982) and Loomes and Sugden (1982), is an alternative behavioral decision theory that can be used to quantify the psychological behavior of regret aversion of decision makers in the decision-making process. It has been used in some studies to solve decisionmaking problems considering the psychological behavior of decision makers. Zhang et al. (2016) used regret theory for the decision making with an air-fighter selection problem. Peng and Yang (2017) applied regret theory and prospect theory in the decision process to solve stochastic multi-criteria decision-making problem. Therefore, GDM based on IVPFLVs and regret theory can be used to select the most suitable historical case.

In the real world, when an emergency event escalates into different stages and more information is collected over time, the emergency decision should be modified dynamically to improve the emergency response. Few studies have considered the dynamics of emergencies (Ren et al. 2017; Wang et al. 2018; Zhang et al. 2018). Therefore, it is necessary to consider the dynamic evolution of emergencies in EDM. Against this background, considering the advantages of CBR and GDM, a dynamic method based on case retrieval and GDM, called dynamic case-based reasoning group decision making (CBRGDM), is proposed to generate a suitable alternative in EDM.

The novelties of the developed approach include the following aspects: (1) Because of the dynamic nature of emergencies, our proposed method of generating emergency alternatives takes into account the adjustment of emergency alternatives. Thus, we can better deal with emergencies according to the evolution of emergencies. (2) 
We use an improved GDM method to select the most feasible historical case, in which we apply IVPFLVs to represent fuzzy information and regret theory to express the decision makers' psychological behavior. (3) This method not only considers the similarity between the historical cases and the target case but also the evaluation of the decision makers. Therefore, the results are more consistent with the actual decision-making process.

The remainder of this article is organized as follows. Section 2 reviews related concepts and definitions. Section 3 describes the proposed dynamic CBRGDM method for solving EDM problems. Section 4 provides an empirical case study and a comparison analysis that illustrate the efficacy and practicability of the proposed method. Section 5 presents the conclusion and future research directions.

\section{Preliminaries}

In this section, the steps of case retrieval are introduced. Then, the concept of IVPFLVs and regret theory are reviewed.

\subsection{Case Retrieval}

Case retrieval is an important step in CBR. Its central issue is to identify similar historical cases through similarity measurement. The following are the steps involved in case retrieval:

Step 1 Calculate the attribute distance/similarity

Attribute distance is often calculated using either Manhattan distance or Euclidian distance. However, these attribute distance functions can be applied only to linear numeric attributes. To overcome this drawback, Li and Sun (2009) proposed a Gaussian distance formula. Furthermore, attribute distance formulas - that is, attribute similarity functions without the distance value-have been used frequently. Examples of these are the inverse exponential function (Fan et al. 2014) and gray correlation degree ( $\mathrm{Li}$ and Sun 2009). The above methods are for numerical data. However, given the complexity of the data type, fuzzy attribute distance/similarity functions have also been proposed (Fan et al. 2014; Zheng et al. 2019).

\section{Step 2 Calculate the case similarities}

First, attribute weights should be determined. Attribute weights can be determined using three methods. The first is the subjective method, such as the analytic hierarchy process (Park and Han 2002). The second is the objective method, mainly statistical methods and machine learning methods, such as optimization models (Zhao and Yu 2011), functions based on gray correlation degree (Han and Cao 2015), membrane computing (Yan et al. 2014), and neural network (Biswas et al. 2017). The third is a mixture of the two. Then, we can aggregate the attribute distance/similarity and attribute weight to obtain the case similarities. The most common method is linear weighting.

Step 3 Identify the similar historical case set

When the case similarities have been determined, the threshold of case similarity needs to be determined. In general, the decision makers make decisions based on their own experience and knowledge. Once the similarity threshold is determined, the similar case set can be obtained.

\subsection{Interval-Valued Pythagorean Fuzzy Linguistic Variables}

Definition 1 (Du et al. 2017) Let $\Psi$ be a finite universe of discourse, and $\mathrm{S}$ be a continuous linguistic term set; then, an interval-valued Pythagorean fuzzy linguistic set (IVPFLS) in $\Psi$ can be proposed as follows:

$\widetilde{D}=\left\{\left\langle x,\left[s_{\theta}(x),\left[u_{\widetilde{D}}^{-}(x), u_{\widetilde{D}}^{+}(x)\right],\left[v_{\bar{D}}^{-}(x), v_{\widetilde{D}}^{+}(x)\right]\right]\right\rangle \mid x \in \Psi\right\}$

Here, for $s_{\theta}(x) \in S,\left[u_{\widetilde{\sim}}^{-}(x), u_{\widetilde{D}}^{+}(x)\right]$ and $\left[v_{\widetilde{\sim}}^{-}(x), v_{\widetilde{D}}^{+}(x)\right]$ are two interval values and indicate the membership degree and non-membership degree of the element $x \in \Psi$, respectively, $\left[u_{\vec{D}}^{-}(x), u_{\vec{D}}^{+}(x)\right] \in[0,1],\left[v_{\vec{D}}^{-}(x), v_{\vec{D}}^{+}(x)\right] \in[0,1]$, and for each $\gamma \in\left[u_{\vec{D}}^{\sim}(x), u_{\vec{D}}^{+}(x)\right]$ and $\eta \in\left[v_{\vec{D}}^{-}(x), v_{\vec{D}}^{+}(x)\right]$, they satisfy $\gamma^{2}+\eta^{2} \leq 1$. For simplicity, the expression $\widetilde{d}=$ $\left\{\left\langle\left[s_{\theta}(x),\left[u_{\widetilde{D}}^{-}(x), u_{\widetilde{D}}^{+}(x)\right],\left[v_{\vec{D}}^{-}(x), v_{\vec{D}}^{+}(x)\right]\right]\right\rangle\right\}$ is called an interval-valued Pythagorean fuzzy linguistic number (IVPFLN).

Definition 2 (Ding et al. 2019) Let $\widetilde{d}=$ $\left\{\left\langle\left[s_{\theta}(x),\left[u_{\widetilde{D}}^{-}(x), u_{\widetilde{D}}^{+}(x)\right],\left[v_{\widetilde{D}}^{-}(x), v_{\widetilde{D}}^{+}(x)\right]\right]\right\rangle\right\} \quad$ be $\quad$ an IVPFLN; it can be transformed into an interval-valued variable, which is shown as:

$$
\begin{aligned}
A(\widetilde{d})= & {\left[\frac{\theta}{2}\left(1+\left(u_{\vec{D}}^{\overline{\widetilde{\tau}}}(x)\right)^{2}-\left(u_{\vec{D}}^{+}(x)\right)^{2}\right), \frac{\theta}{2}\left(1+\left(v_{\bar{D}}^{\overline{\widetilde{\tau}}}(x)\right)^{2}\right.\right.} \\
& \left.\left.-\left(v_{D}^{+}(x)\right)^{2}\right)\right]
\end{aligned}
$$

Definition 3 (Du et al. 2017) Let $\widetilde{D}=$ $\left\{\widetilde{d}_{1}, \widetilde{d}_{2}, \ldots, \tilde{d}_{j}, \ldots, \widetilde{d}_{n}\right\}$ be a vector of IVPFLNs, where 
$\widetilde{d}_{j}=\left\{\left\langle\left[s_{\theta_{j}}(x),\left[u_{\tilde{d}_{j}}^{-}(x), u_{\tilde{d}_{j}}^{+}(x)\right],\left[v_{d_{j}}^{-}(x), v_{\tilde{d}_{j}}^{+}(x)\right]\right]\right\rangle\right\} ; \quad$ then, the interval-valued Pythagorean fuzzy linguistic weighted averaging (IVPFLWA) operator is defined as follows:

$$
\begin{aligned}
& \operatorname{IVPFLWA}\left(\tilde{d}_{1}, \tilde{d}_{2}, \ldots, \tilde{d}_{n}\right) \\
& =\left\{\left\langle\sum _ { \sum _ { j = 1 } ^ { n } w _ { j } \theta _ { j } } \left[\sqrt{1-\prod_{j=1}^{n}\left(1-u_{\tilde{d}_{j}}^{-2}\right)^{w_{j}}},\right.\right.\right. \\
& \times \sqrt{\left.\left.1-\prod_{j=1}^{n}\left(1-u_{\tilde{d}_{j}^{+2}}^{+w_{j}}\right]\left[\prod_{j=1}^{n} v_{\tilde{d}_{j}}^{-w_{j}}, \prod_{j=1}^{n} v_{\widetilde{d}_{j}}^{+w_{j}}\right]\right\rangle\right\}}
\end{aligned}
$$

Here, $w_{j}$ is the weight of $\widetilde{d}_{j}$, satisfying $0 \leq w_{j} \leq 1$ $(j=1,2, \ldots, n)$ and $\sum_{j=1}^{n} w_{j}=1$.

\subsection{Regret Theory}

Decision makers' psychological behaviors are expressed by regret theory (Laciana and Weber 2008) in this study. Regret theory holds that the decision maker not only pays attention to the results obtained by the selected alternative but also pays attention to the possible results if other alternatives are chosen (Bell et al. 1982; Loomes et al. 1982). Therefore, the perceived utility of decision makers consists of two parts: the utility function of the current result and the regret-rejoice function in comparison with other results.

The decision maker's perceived utility value of alternative $A_{i}(i \in\{1,2, \ldots, m\})$, proposed by Quiggin et al. (1997), is defined as follows:

$u_{i}=v\left(x_{i}\right)+R\left(v\left(x_{i}\right)-v\left(x^{*}\right)\right)$

where $x_{i}$ represents the result of alternative $A_{i}$, $x^{*}=\max \left\{x_{i} \mid i \in\{1,2, \ldots, m\}\right\}, v\left(x_{i}\right)$ represents the utility value of $x_{i}$, and $R\left(v\left(x_{i}\right)-v\left(x^{*}\right)\right)$ represents the regret-rejoice function. When $R\left(v\left(x_{i}\right)-v\left(x^{*}\right)\right)>0, R\left(v\left(x_{i}\right)-\right.$ $\left.v\left(x^{*}\right)\right)$ denotes the rejoice value. When $R\left(v\left(x_{i}\right)-v\left(x^{*}\right)\right)<0, R\left(v\left(x_{i}\right)-v\left(x^{*}\right)\right)$ denotes the regret value.

According to Chorus (2012), the utility function $v\left(x_{i}\right)$ can be defined as follows:

$v\left(x_{i}\right)=\left(x_{i}\right)^{\alpha}$

Here, $\alpha$ is the risk aversion coefficient of a decision maker, $0<\alpha<1$. The greater the value of $\alpha$, the greater the degree of risk aversion of a decision maker.

According to Zhang et al. (2016), the regret-rejoice function $R\left(v\left(x_{i}\right)-v\left(x^{*}\right)\right)$ can be defined as follows:

$R\left(v\left(x_{i}\right)-v\left(x^{*}\right)\right)=1-\exp \left(-\delta\left(v\left(x_{i}\right)-v\left(x^{*}\right)\right)\right)$

Here, $\delta$ is the risk aversion coefficient of a decision maker. The greater the value of $\delta$, the greater the degree of risk aversion of a decision maker. Figure 1 shows the effect of $\delta$ on the regret-rejoice function $R\left(v\left(x_{i}\right)-v\left(x^{*}\right)\right)$.

\section{A Dynamic Emergency Decision-Making Method}

In this section, a dynamic CBR method is presented for generating alternatives in a GDM environment. Assuming $Z=\left\{z_{1}, z_{2}, \ldots, z_{h}\right\}$ is the state set, where $z_{t}$ represents the $t$ th state, namely, when the emergency develops into $z_{t}$, the alternative should be considered to adjust, $t \in\{1,2, \ldots, h\}$. Figure 2 shows the basic procedure of the proposed method. First, the similar historical cases are identified by searching the historical case base. Second, the evaluated values of the similar historical cases are obtained by aggregating the evaluations of the decision makers with the assistance of the regret theory. Third, the alternative of the target case for state $z_{t}$ is obtained from the case similarities between the target case in state $z_{t}$ and the similar historical cases and the comprehensive utilities of the similar historical cases. Furthermore, when the emergency develops into the state $z_{t+1}$, we should consider the adjustment of alternative according to the similarity between the most suitable historical case in state $z_{t}$ and the target case in state $z_{t+1}$.

\subsection{Identifying Similar Historical Cases}

This section describes a method to identify the similar historical cases according to the target case and the historical case base.

There are two types of cases in the case base: historical cases and the target case. Let $c_{j}$ denote the $j$ th historical case, $j \in\{1,2, \ldots, n\}$, and $c_{0}^{(t)}$ denote the target case in state $z_{t}$. Let $p_{i}$ denote the $i$ th problem attribute, $i \in\{1,2, \ldots, m\}$. Let $x_{j i}$ denote the problem attribute value with regard to the historical case $c_{j}$. Let $x_{0 i}^{(t)}$ denote the problem attribute value with regard to the target case $c_{0}^{(t)}$. Let $w_{i}^{P}$ denote the weight of attribute $p_{i}$, such that $\sum_{i=1}^{m} w_{i}^{P}=1$, and $0 \leq w_{i}^{P} \leq 1$.

In the real case base, the type of case attribute is diverse. Fan et al. (2014) and Zheng et al. (2019) proposed hybrid similarity measurement. Fan et al. (2014) considered five formats of attribute values: crisp symbols, crisp numbers, interval numbers, fuzzy linguistic variables, and random variables. Zheng et al. (2019) considered four formats of attribute values: crisp numbers, interval numbers, multigranularity linguistic variables, and intuitionistic fuzzy numbers. In this study, we considered the following formats of attribute values: crisp numbers, interval numbers, 
Fig. 1 Regret-rejoice function $R\left(v\left(x_{i}\right)-v\left(x^{*}\right)\right)$

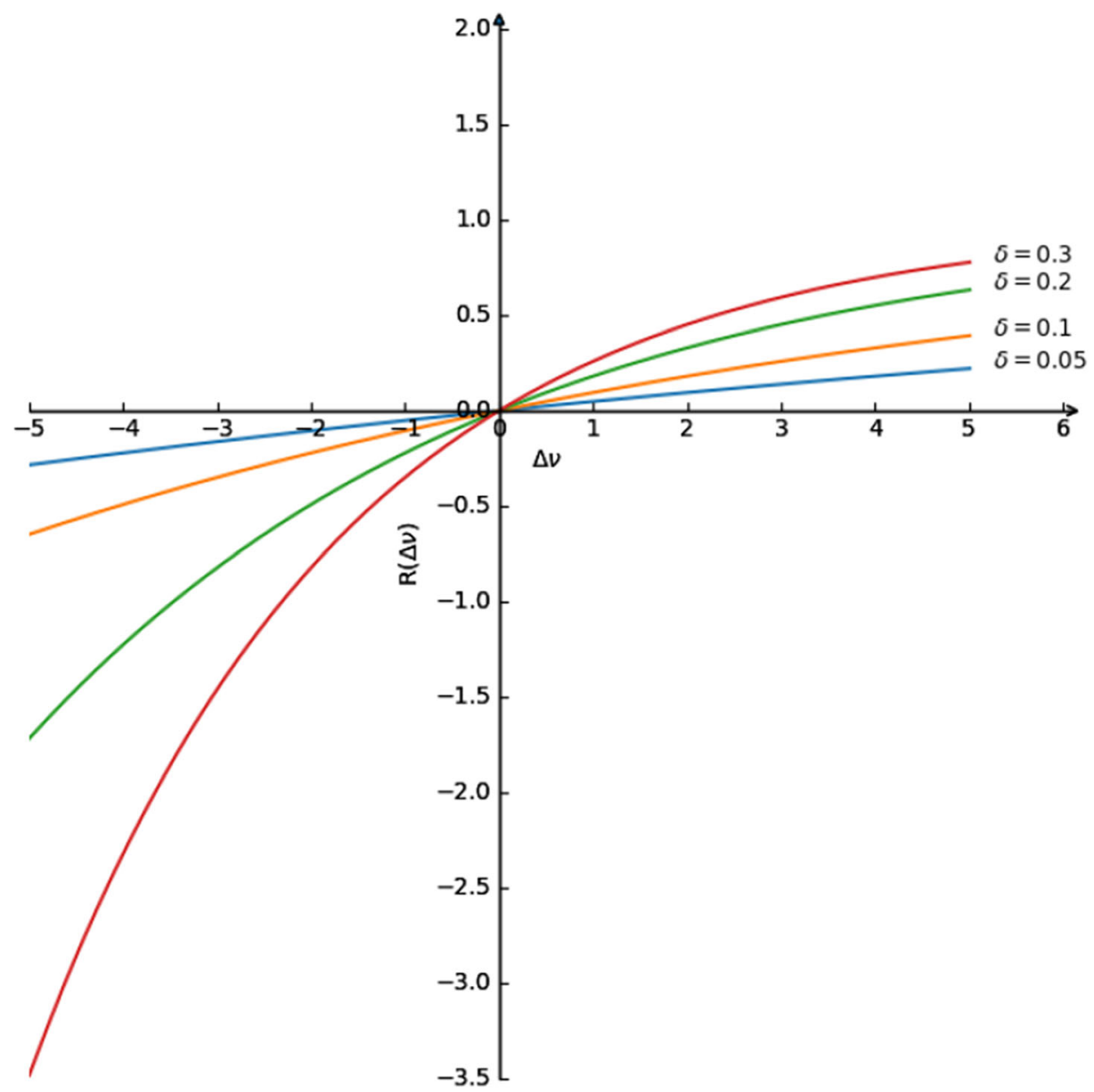

and fuzzy linguistic variables. On this basis, the case similarity measurement can be defined as follows.

Step 1 Calculate the attribute distances

When attributes $x_{j i}$ and $x_{0 i}^{(t)}$ are crisp numbers, the attribute distance $\Delta\left(x_{0 i}^{(t)}, x_{j i}\right)$ is given as follows:

$\Delta\left(x_{0 i}^{(t)}, x_{j i}\right)=\frac{\sqrt{\left(x_{0 i}^{(t)}-x_{j i}\right)^{2}}}{\Delta_{i}^{(t) \max }}$

Here, $\Delta_{i}^{(t) \max }=\max \left\{\sqrt{\left(x_{0 i}^{(t)}-x_{j i}\right)^{2}} \mid j \in\{1,2, \ldots, n\}\right\}$.

When attributes $x_{j i}$ and $x_{0 i}^{(t)}$ are interval numbers, that is, $x_{j i}=\left[x_{j i}^{-}, x_{j i}^{+}\right]$and $x_{0 i}^{(t)}=\left[x_{0 i}^{(t)-}, x_{0 i}^{(t)+}\right]$, the attribute distance $\Delta\left(x_{0 i}^{(t)}, x_{j i}\right)$ is given as follows:

$\Delta\left(x_{0 i}^{(t)}, x_{j i}\right)=\frac{\sqrt{\left(x_{0 i}^{(t)-}-x_{j i}^{-}\right)^{2}+\left(x_{0 i}^{(t)+}-x_{j i}^{+}\right)^{2}}}{\Delta_{i}^{(t) \max }}$

Here, $\quad \Delta_{i}^{(t) \max }=\max \left\{\sqrt{\left(x_{0 i}^{(t)-}-x_{j i}^{-}\right)^{2}+\left(x_{0 i}^{(t)+}-x_{j i}^{+}\right)^{2}} \mid j\right.$ $\in\{1,2, \ldots, n\}\}$
When attributes $x_{j i}$ and $x_{0 i}^{(t)}$ are fuzzy linguistic variables, they can be transformed into triangular fuzzy numbers. According to Jiang et al. (2008), a linguistic variable $\tilde{y}_{k}$ $(0 \leq k \leq T-1)$ can be represented using the triangular fuzzy number $\tilde{y}_{k}=\left(y_{k}^{a}, y_{k}^{b}, y_{k}^{c}\right)$, that is,

$$
\begin{aligned}
\tilde{y}_{k} & =\left(y_{k}^{a}, y_{k}^{b}, y_{k}^{c}\right) \\
& =(\max ((k-1) / T, 0), k / T, \min ((k+1) / T, 1))
\end{aligned}
$$

Here, $y_{k}^{a}, y_{k}^{b}$, and $y_{k}^{c}$ are real numbers, $0 \leq y_{k}^{a} \leq y_{k}^{b} \leq y_{k}^{c} . T$ is the number of linguistic variables.

Thus, the attribute distance $\Delta\left(x_{0 i}^{(t)}, x_{j i}\right)$ is given as follows:

$\Delta\left(x_{0 i}^{(t)}, x_{j i}\right)=\frac{\sqrt{\left(x_{0 i}^{(t) a}-x_{j i}^{a}\right)^{2}+\left(x_{0 i}^{(t) b}-x_{j i}^{b}\right)^{2}+\left(x_{0 i}^{(t) c}-x_{j i}^{c}\right)^{2}}}{\Delta_{i}^{(t) \max }}$

Here, $\Delta_{i}^{(t) \max }=$

$\max \left\{\sqrt{\left(x_{0 i}^{(t) a}-x_{j i}^{a}\right)^{2}+\left(x_{0 i}^{(t) b}-x_{j i}^{b}\right)^{2}+\left(x_{0 i}^{(t) c}-x_{j i}^{c}\right)^{2}} \mid j\right.$ $\in\{1,2, \ldots, n\}\}$. 


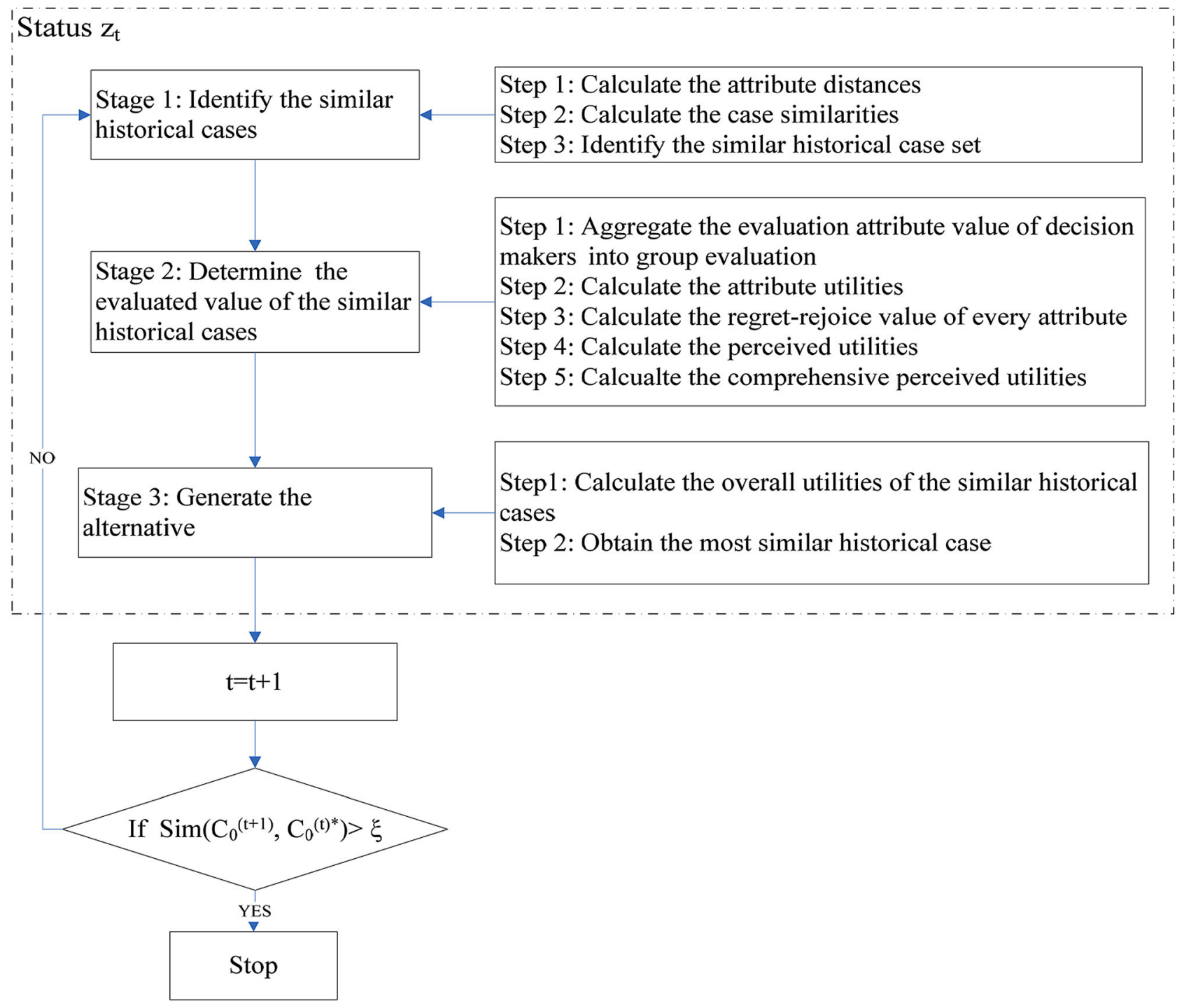

Fig. 2 Flowchart of the proposed dynamic emergency decision-making method

Step 2 Calculate the case similarities $\operatorname{Sim}\left(c_{0}^{(t)}, c_{j}\right)$

Based on the attribute distance $\Delta\left(x_{0 i}^{(t)}, x_{j i}\right)$, the case similarity $\operatorname{Sim}\left(c_{0}^{(t)}, c_{j}\right)$ can be obtained as follows:

$\operatorname{Sim}\left(c_{0}^{(t)}, c_{j}\right)=1-\sum_{i=1}^{m} w_{i}^{P} \Delta\left(x_{0 i}^{(t)}, x_{j i}\right)$

Here, $w_{i}^{P}$ is given by the decision maker according to his/her experience. Clearly, $\operatorname{Sim}\left(c_{0}^{(t)}, c_{j}\right) \in[0,1]$. The greater the value of $\operatorname{Sim}\left(c_{0}^{(t)}, c_{j}\right)$, the more similar the historical case $c_{j}$ is to the target case $c_{0}^{(t)}$.

Step 3 Identify the similar historical case set $C^{(t) S i m}$
Decision makers select the top $\lambda(0 \leq \lambda \leq n)$ historical cases according to their experience. If $\operatorname{Sim}\left(c_{0}^{(t)}, c_{j}\right)$ ranks the top $\lambda$, the corresponding historical case $c_{j}$ will be regarded as the similar historical case. On this basis, the similar historical case set $C^{(t) \operatorname{Sim}}$ in state $z_{t}$ is formed, where $C^{(t) \operatorname{Sim}}=\left\{G_{a}^{t} \mid a \in\{1,2, \ldots, \lambda\}\right\}$, where $G_{a}^{(t)} \in\left\{c_{j}\right\}$.

\subsection{Determine the Evaluated Value of the Similar Historical Cases}

Several decision makers evaluate the alternatives of the similar historical cases for applicability to the target case $c_{0}^{(t)}$.

Let $e_{r}$ denote the $r$ th decision maker, $r \in\{1,2, \ldots, M\}$. Their corresponding weight vector is 
$W=\left\{w_{1}^{e}, w_{2}^{e}, \ldots, w_{M}^{e}\right\}, \quad$ such that $\quad \sum_{r=1}^{M} w_{r}^{e}=1, \quad$ and $0 \leq w_{r}^{e} \leq 1$. Let $R_{l}$ denote the $l$ th evaluation attribute, $l \in\{1,2, \ldots, L\}$. Let $W^{v(t)}=\left\{w_{1}^{v(t)}, w_{2}^{v(t)}, \ldots, w_{L}^{v(t)}\right\}$ be the evaluation attribute weight vector in state $z_{t}$, such that $\sum_{l=1}^{L} w_{l}^{v(t)}=1$, and $0 \leq w_{l}^{v(t)} \leq 1$. Let $q_{a l}^{r(t)}$ denote the evaluation attribute value of the $r$ th expert with regard to the similar historical case $G_{a}^{(t)}$ in state $z_{t}$, and $q_{a l}^{r(t)}$ is an IVPFLV, that is, $\quad q_{a l}^{r(t)}=\left\{<\left[s_{\theta a l}^{r(t)},\left[u_{a l}^{r(t)-}, u_{a l}^{r(t)+}\right]\right.\right.$, $\left.\left.\left[v_{a l}^{r(t)-}, v_{a l}^{r(t)+}\right]\right]>\right\}$.

Step 1 Aggregate the evaluation attribute value of decision makers $q_{a l}^{r(t)}$ into group evaluation $p_{a l}^{(t)}$

According to the IVPFLWA operator, the group evaluation $p_{a l}^{(t)}$ is gained as

$$
\begin{aligned}
p_{a l}^{(t)} & =\left\{S_{\beta},\left[\mu_{a l}^{(t)-}, \mu_{a l}^{(t)+}\right],\left[v_{a l}^{(t)-}, v_{a l}^{(t)+}\right]\right\} \\
& =\operatorname{IVPFLWA}\left(q_{a l}^{1(t)}, q_{a l}^{2(t)}, \ldots, q_{a l}^{M(t)}\right) \\
& =\left\{\left\langleS_{\sum_{r=1}^{M} w_{r}^{e} \theta_{a l}},\left[\sqrt{1-\prod_{r=1}^{M}\left(1-\left(u_{a l}^{r(t)-}\right)^{2}\right)^{w_{r}^{e}},}\right.\right.\right. \\
& \sqrt{\left.\left.\left.1-\prod_{r=1}^{M}\left(1-\left(u_{a l}^{r(t)+}\right)^{2}\right)^{w_{r}^{e}}\right],\left[\prod_{r=1}^{M}\left(v_{a l}^{r(t)-}\right)^{w_{r}^{e}}, \prod_{r=1}^{M}\left(v_{a l}^{r(t)+}\right)^{w_{r}^{e}}\right]\right\rangle\right\}}
\end{aligned}
$$

Step 2 Calculate the attribute utilities

Step 2.1 Transform $p_{a l}^{(t)}$ into an interval value $p_{a l}^{(t)}=\left[p_{a l}^{(t)-}, p_{a l}^{(t)+}\right]$

According to the transformation method proposed by Ding et al. (2019) and the group evaluation $p_{a l}^{(t)}$, the interval-valued evaluation information is obtained as follows:

$$
\begin{aligned}
p_{a l}^{(t)}= & {\left[p_{a l}^{(t)-}, p_{a l}^{(t)+}\right] } \\
= & {\left[\frac{\beta}{2}\left(1+\left(u_{a l}^{(t)-}\right)^{2}-\left(u_{a l}^{(t)+}\right)^{2}\right), \frac{\beta}{2}\left(1+\left(v_{a l}^{(t)-}\right)^{2}\right.\right.} \\
& \left.\left.-\left(v_{a l}^{(t)+}\right)^{2}\right)\right]
\end{aligned}
$$

Step 2.2 Normalize the interval value $\bar{p}_{a l}^{(t)}=\left[\bar{p}_{a l}^{(t)-}, \bar{p}_{a l}^{(t)+}\right]$ Based on the interval value $p_{a l}^{(t)}=\left[p_{a l}^{(t)-}, p_{a l}^{(t)+}\right]$, the normalized interval value $\bar{p}_{a l}^{(t)}=\left[\bar{p}_{a l}^{(t)-}, \bar{p}_{a l}^{(t)+}\right]$ is derived as follows:

$\bar{p}_{a l}^{(t)-}= \begin{cases}\left(p_{a l}^{(t)-}-g_{l}^{(t)}\right) /\left(q_{l}^{(t)}-g_{l}^{(t)}\right), & p_{a l}^{(t)} \in N_{b} \\ \left(q_{l}^{(t)}-p_{a l}^{(t)-}\right) /\left(q_{l}^{(t)}-g_{l}^{(t)}\right), & p_{a l}^{(t)} \in N_{c}\end{cases}$
$\bar{p}_{a l}^{(t)+}= \begin{cases}\left(p_{a l}^{(t)+}-g_{l}^{(t)}\right) /\left(q_{l}^{(t)}-g_{l}^{(t)}\right), & p_{a l}^{(t)} \in N_{b} \\ \left(q_{l}^{(t)}-p_{a l}^{(t)+}\right) /\left(q_{l}^{(t)}-g_{l}^{(t)}\right), & p_{a l}^{(t)} \in N_{c}\end{cases}$

Here,

$$
g_{l}^{(t)}=\min \left\{p_{a l}^{(t)-} \mid a \in\{1,2, \ldots, \lambda\}\right\},
$$

$q_{l}^{(t)}=\max \left\{p_{a l}^{(t)+} \mid a \in\{1,2, \ldots, \lambda\}\right\}, \quad N_{b} \quad$ represents the benefit attribute, and $N_{c}$ represents the cost attribute.

Step 2.3 Calculate the attribute utility $\varphi_{a l}^{(t)}$

As the interval number comes from the calculation of random sampling, the attribute value $\pi$ is considered a random value in the interval $\left[\bar{p}_{a l}^{(t)-}, \bar{p}_{a l}^{(t)+}\right]$ and obeys a certain distribution. Based on this, the utility $\varphi_{a l}^{(t)}$ is derived as follows:

$\varphi_{a l}^{(t)}=\int_{\bar{p}_{a l}^{(t)-}}^{\bar{p}_{a l}^{(t)+}} v(\pi) f_{a l}^{(t)}(\pi) d x$

Here, $v(\pi)$ is the utility function. As the decision maker is risk-averse in EDM, it is more appropriate to use a concave function with a monotonically increasing trend. Therefore, the power function is employed as the utility function in this study, that is, $v(\pi)=\pi^{\alpha} . f_{a l}^{(t)}(\pi)$ is the probability distribution function, and it usually obeys uniform and normal distributions. In this study, we considered that $f_{a l}^{(t)}(\pi)$ obeys a uniform distribution, that is, $f_{a l}^{(t)}(\pi)=\frac{1}{\bar{p}_{a l}^{(t)+}-\bar{p}_{a l}^{(t)-}}$.

Step 3 Calculate the regret-rejoice value $h_{a l}^{(t)}$ of every attribute

According to Eq. 6, the regret-rejoice value $h_{a l}^{(t)}$ is obtained as follows:

$h_{a l}^{(t)}=1-\exp \left[-\delta\left(\varphi_{a l}^{(t)}-\varphi_{l}^{(t) *}\right)\right]$

Here, $\varphi_{l}^{(t) *}=\max \left\{\varphi_{a l}^{(t)} \mid a \in\{1,2, \ldots, \lambda\}\right\}$.

Step 4 Calculate the perceived utilities $Q_{a l}^{(t)}$

According to Eq. 4, the perceived utility can be expressed as follows:

$Q_{a l}^{(t)}=\varphi_{a l}^{(t)}+h_{a l}^{(t)}$

Step 5 Calculate the comprehensive perceived utilities

Step 5.1 Determine the evaluation attribute weights $w_{l}^{v(t)}$

The distance-based method (Yu et al. 2011) can be used to determine the weights of the attributes in accordance with the distance between the attribute value and the extreme value. According to the distance-based weighting method, the greater the positive distance, the more important is the attribute. Therefore, a higher weight value should be assigned to the attribute. The distance-based weighting method can be described as follows:

$d_{l}^{(t)+}=\sqrt{\sum_{a=1}^{\lambda}\left(Q_{a l}^{(t)}-Q_{l}^{(t) \max }\right)^{2}}$

$d_{l}^{(t)-}=\sqrt{\sum_{a=1}^{\lambda}\left(Q_{a l}^{(t)}-Q_{l}^{(t) \min }\right)^{2}}$ 
$\chi_{l}^{(t)}=\frac{d_{l}^{(t)+}}{d_{l}^{(t)+}+d_{l}^{(t)-}}$

$w_{l}^{v(t)}=\frac{\chi_{l}^{(t)}}{\sum_{l=1}^{L} \chi_{l}^{(t)}}$

where $Q_{l}^{(t) \max }=\max _{1 \leq a \leq \lambda}\left\{Q_{a l}^{(t)}\right\}, Q_{l}^{(t) \min }=\min _{1 \leq a \leq \lambda}\left\{Q_{a l}^{(t)}\right\}$.

Step 5.2 Determine the comprehensive perceived utility $V_{a}^{(t)}$

$V_{a}^{(t)}=\sum_{l=1}^{L} w_{l}^{v(t)} Q_{a l}^{(t)}$

Clearly, a higher value of $V_{a}^{(t)}$ corresponds to a better alternative.

\subsection{Generate the Alternative}

Step 1 Calculate the overall utilities of the similar historical cases

Once the case similarity with regard to similar historical cases in state $z_{t} \operatorname{Sim}\left(c_{0}^{(t)}, c_{a}\right)$ and the comprehensive perceived utility in state $z_{t} V_{a}^{(t)}$ are obtained, the overall utilities of each similar historical case in state $z_{t} U_{a}^{(t)}$ can be calculated using the simple additive method, as follows:

$U_{a}^{(t)}=\operatorname{Sim}\left(c_{0}^{(t)}, c_{a}\right) * V_{a}^{(t)}$

The greater the value of $U_{a}^{(t)}$, the better the alternative of historical case $c_{j}$ in state $z_{t}$.

Step 2 Obtain the most similar historical case

Based on the value of $U_{a}^{(t)}$, the ranking of the similar historical cases can be obtained. According to the ranking of the similar historical cases, the most similar historical case $c^{(t) *}$ can be gain. Then, the decision makers can select or adjust the alternative of the best similar historical case $c^{(t) *}$ to cope with the emergency.

\subsection{Alternative Dynamic Adjustment}

Let $t=t+1$, that is, the target case develops into $c_{0}^{(t+1)}$. Then we should consider the adjustment of alternative. If $\operatorname{Sim}\left(c_{0}^{(t+1)}, c^{(t) *}\right) \geq \xi$, the alternative generated at state $z_{t}$ continues to be used, where $\xi$ is the state case similarity threshold and is given by decision maker(s). Otherwise, the alternative generated at state $z_{t}$ should be adjusted by repeating the above steps to generate a new alternative.

\section{Illustrative Example}

In this section, the emergency alternative for a gas explosion is generated as an example to demonstrate the applicability and practicability of the proposed dynamic CBRGDM method.

\subsection{Implementation and Results}

Company A is a coal company in area B of China. To better deal with gas explosions, company A collected 10 historical cases $\left(c_{1}, c_{2}, \ldots, c_{10}\right)$. $\mathrm{A}$ gas explosion that occurred recently is considered the target case $c_{0}^{(t)}$. The emergency response to gas explosion is divided into two states: one is gold rescue within $72 \mathrm{~h}$, and the other is urgent rescue within 4-10 days. Five attributes are considered for every case: the number of underground personnel ( $p_{1}$, unit: person), gas concentration $\left(p_{2}\right.$, unit: $\left.\%\right)$, CO concentration $\left(p_{3}\right.$, unit: $\left.\%\right)$, ventilation $\left(p_{4}\right)$, and $\mathrm{O}_{2}$ concentration $\left(p_{5}\right.$, unit: \%). The attribute weight vector provided by the decision makers is $w^{P}=\{0.2,0.2,0.2,0.2,0.2\}$. Among them, $p_{1}$ is a crisp number, $p_{2}, p_{3}$, and $p_{5}$ are interval numbers, and $p_{4}$ is a linguistic variable, whose linguistic assessment set is $S^{1}=$ $\{D B:$ definitely bad, $V B:$ very good, $B:$ bad, $M:$ medium, $G:$ good, $V G:$ very good, $D G$ :definitely good $\}$. Table 1 lists the attribute values of the historical cases and the target case. The decision makers determine the value of $\lambda$ as four. Three decision makers $\left\{e_{1}, e_{2}, e_{3}\right\}$ were invited to make decision for the emergency alternative. They preferred four criteria, including the casualty reduction rate $\left(R_{1}\right)$, property loss rate $\left(R_{2}\right)$, response timeliness $\left(R_{3}\right)$, and control effect $\left(R_{4}\right)$. For each state, the linguistic evaluations given by the three decision makers for the similar case set

Table 1 Problem attributes for the historical cases and the target case

\begin{tabular}{llllll}
\hline & $p_{1}$ & $p_{2}$ & $p_{3}$ & $p_{4}$ & $p_{5}$ \\
\hline $\mathrm{c}_{1}$ & 230 & {$[0.13,0.21]$} & {$[0.40,0.53]$} & $\mathrm{M}$ & {$[0.03,0.07]$} \\
$\mathrm{c}_{2}$ & 128 & {$[0.14,0.29]$} & {$[0.22,0.35]$} & $\mathrm{DG}$ & {$[0.09,0.13]$} \\
$\mathrm{c}_{3}$ & 116 & {$[0.12,0.22]$} & {$[0.13,0.31]$} & $\mathrm{DG}$ & {$[0.04,0.06]$} \\
$\mathrm{c}_{4}$ & 185 & {$[0.12,0.23]$} & {$[0.46,0.67]$} & $\mathrm{G}$ & {$[0.04,0.06]$} \\
$\mathrm{c}_{5}$ & 147 & {$[0.07,0.13]$} & {$[0.12,0.32]$} & $\mathrm{VG}$ & {$[0.06,0.07]$} \\
$\mathrm{c}_{6}$ & 184 & {$[0.15,0.21]$} & {$[0.45,0.63]$} & $\mathrm{M}$ & {$[0.08,0.10]$} \\
$\mathrm{c}_{7}$ & 132 & {$[0.06,0.14]$} & {$[0.17,0.26]$} & $\mathrm{G}$ & {$[0.04,0.05]$} \\
$\mathrm{c}_{8}$ & 178 & {$[0.12,0.18]$} & {$[0.32,0.47]$} & $\mathrm{B}$ & {$[0.03,0.06]$} \\
$\mathrm{c}_{9}$ & 165 & {$[0.15,0.23]$} & {$[0.28,0.37]$} & $\mathrm{G}$ & {$[0.05,0.08]$} \\
$\mathrm{c}_{10}$ & 218 & {$[0.08,0.17]$} & {$[0.42,0.65]$} & $\mathrm{VG}$ & {$[0.03,0.06]$} \\
$\mathrm{c}_{0}^{(1)}$ & 152 & {$[0.12,0.22]$} & {$[0.53,0.63]$} & $\mathrm{G}$ & {$[0.05,0.07]$} \\
\hline
\end{tabular}


are represented by IVPFLNs based on the following linguistic term set:

$$
\begin{aligned}
S^{2} & =\left\{s_{0}=\text { very poor }, s_{1}=\text { poor }, s_{2}=\text { slightly poor, } s_{3}\right. \\
& =\text { fair, } s_{4}=\text { slightly good }, s_{5}=\text { good }, s_{6} \\
& =\text { very good }\}
\end{aligned}
$$

Owing to space limitations, we only list the first state $z_{1}$ evaluation information, as listed in Table 2. The state case similarity threshold $\xi$ is given as 0.8 by the decision makers.

The decision process and results of the proposed CBRGDM method for generating the most suitable alternative in two states are summarized as follows.

First, we introduce the steps of generating the alternative in state $z_{1}$.

Stage 1 Identify the similar historical cases

Step 1 Calculate the attribute distances

For crisp attributes, the attribute distance $\Delta\left(x_{0 i}^{(1)}, x_{j i}\right)$ is calculated by Eq. 7; for interval number attributes, the attribute distance $\Delta\left(x_{0 i}^{(1)}, x_{j i}\right)$ is calculated by Eq. 8; for fuzzy linguistic variable attributes, the attribute distance $\Delta\left(x_{0 i}^{(1)}, x_{j i}\right)$ is calculated by Eqs. 9-10, and the computation results can be found in Table 3 .

Step 2 Calculate the case similarities

Using Eq. 11, we can determine the case similarity $\operatorname{Sim}\left(c_{0}^{(1)}, c_{j}\right)(j=1,2, \ldots, n)$, that is, $\operatorname{Sim}\left(c_{0}^{(1)}, c_{1}\right)=0.6689$, $\operatorname{Sim}\left(c_{0}^{(1)}, c_{2}\right)=0.2620, \operatorname{Sim}\left(c_{0}^{(1)}, c_{3}\right)=0.4968, \operatorname{Sim}\left(c_{0}^{(1)}, c_{4}\right)=$ 0.7101, $\quad \operatorname{Sim}\left(c_{0}^{(1)}, c_{5}\right)=0.4603, \quad \operatorname{Sim}\left(c_{0}^{(1)}, c_{6}\right)=0.6079$, $\operatorname{Sim}\left(c_{0}^{(1)}, c_{7}\right)=0.4924, \operatorname{Sim}\left(c_{0}^{(1)}, c_{8}\right)=0.4913, \operatorname{Sim}\left(c_{0}^{(1)}, c_{9}\right)=$ $0.7378, \operatorname{Sim}\left(c_{0}^{(1)}, c_{10}\right)=0.5011$.

Step 3 Identify the similar historical case set

Decision makers select the top four historical cases according to their experience. Hence, a similar case set is determined as $G^{(1) \operatorname{Sim}}=\left\{G_{1}^{(1)}, G_{2}^{(1)}, G_{3}^{(1)}, G_{4}^{(1)}\right\}=$ $\left\{c_{1}, c_{4}, c_{6}, c_{9}\right\}$.

Stage 2 Determine the evaluated value of the similar historical cases

Step 1 To avoid loss of generality, we assume equal weight $w_{r}^{e}$ for all experts. Using Eq. 12, we aggregate the IVPFLN evaluations of the three decision makers $q_{a l}^{r(1)}$ into the group evaluation $p_{a l}^{(1)}$. The results are shown in Table 4.

Step 2 Using Eq. 13, the group IVPFLN evaluations $p_{a l}^{(1)}$ are transformed into the interval value $p_{a l}^{(1)}=\left[p_{a l}^{(1)-}, p_{a l}^{(1)+}\right]$. The interval values $p_{a l}^{(1)}$ are normalized as $\bar{p}_{a l}^{(1)}=$ $\left[\bar{p}_{a l}^{(1)-}, \bar{p}_{a l}^{(1)+}\right]$ using Eqs. 14 and 15. Table 5 lists the results. The utility value $\varphi_{a l}^{(1)}$ is calculated using Eq. 16.
Step 3 The regret-rejoice value $h_{a l}^{(1)}$ is calculated using Eq. 17.

Step 4 The perceived utility $Q_{a l}^{(1)}$ is obtained using Eq. 18. Table 6 lists the results.

Step 5 According to Eqs. 19-22, the evaluation attribute weights $w_{l}^{v(1)}$ are obtained as $w_{1}^{v(1)}=0.2321$, $w_{2}^{v(1)}=0.2230, \quad w_{3}^{v(1)}=0.2615, \quad$ and $\quad w_{4}^{v(1)}=0.2835$. According to Eq. 23, the comprehensive perceived utility $V_{a}^{(1)}$ is calculated as $V_{1}^{(1)}=0.5822, \quad V_{2}^{(1)}=0.6640$, $V_{3}^{(1)}=0.1023$, and $V_{4}^{(1)}=0.6385$.

Stage 3 Generate the alternative

Step 1 According to Eq. 24, the overall utilities of each similar historical case $U_{a}^{(1)}$ is obtained as follows: $U_{1}^{(1)}=0.3539, \quad U_{2}^{(1)}=0.4715, \quad U_{3}^{(1)}=0.0671, \quad$ and $U_{4}^{(1)}=0.4711$.

Step 2 Clearly, the greater the overall utility, the more suitable is the alternative of the similar historical case. Consequently, according to the obtained overall utilities, $U_{2}^{(1)}$ is the maximum and the historical case $c_{4}$ can be selected as the most suitable historical case $c^{(1) *}$.

Stage 4 Alternative dynamic adjustment

In the second state $z_{2}$, the target case is $c_{0}^{(2)}=\{100,[0.08,0.10],[0.2,0.3], V G,[0.01,0.02]\}$.

According to Eqs. 7-11, the case similarity $\operatorname{Sim}\left(c_{0}^{(2)}, c^{(1) *}\right)=0.8139$. As $\operatorname{Sim}\left(c_{0}^{(2)}, c^{(1) *}\right)>\xi$, the decision makers determine that the alternative in state $z_{1}$ is continued to be used.

It is indicated from the computation results, obtained by using the proposed dynamic CBRGDM, that the retrieved historical case $c_{4}$ has the most resemblance to the target case in state $z_{1}$, and no adjustment is required in state $z_{2}$. Thus, the alternative for the historical case $c_{4}$ can be considered as that for Company A.

\subsection{Comparative Analysis and Advantages of the Proposed Approach}

In this subsection, we compare some existing methods with the proposed approach and summarize some advantages of the proposed approach.

\subsubsection{Comparative Analysis}

In this subsection, to verify the effectiveness and practicability of the proposed CBRGDM approach, we compare it with four existing EDM methods, including the EDM based on the CBR method (Fan et al. 2014), called CBR-F; the method based on the CBR and IVPFLWA operator (Du et al. 2017), called CBR-IVPFLWA; the GDM method 
based on the prospect theory (Wang et al. 2015), called CBR-GDMPT; and the GDM method based on IVPFLV and prospect theory (Ding et al. 2019), called CBRIVPFLVPT. The most similar historical cases based on the five approaches for the above case study are shown in Table 7. Some of the observations made from Table 7 are as follows:

1. CBR-F obtains the most similar historical case as a reference for the target case only by case retrieval. The result obtained using the CBR-F method is $c_{9}$. This is because the CBR-F does not consider the opinions of decision makers on similar historical case sets. However, in reality, the most similar historical case is not the most suitable for the target case (Zheng et al. 2018). Therefore, choosing the most appropriate historical case based on the evaluation of similar historical sets by the decision makers is more suitable for the actual decision-making process.

2. The calculated result using the method CBRIVPFLWA is $c_{9}>c_{4}>c_{1}>c_{6}$. This is different from that obtained using the proposed method. This is because CBR-IVPFLWA does not consider the psychological behavior of decision makers. In a real decision-making process, decision makers have their own preferences and psychological behavior; therefore, considering the psychological behavior is more reasonable.

3. The calculated result obtained using the method based on CBR-GDMPT is $c_{4}>c_{1}>c_{9}>c_{6}$. The most suitable case is $c_{4}$, which is the same as that obtained using the proposed method. However, the prospect theory requires determination of the reference point in advance. Furthermore, there are several parameters

Table 2 Evaluation information of the similar historical cases in state $z_{1}$

\begin{tabular}{clllll}
\hline & & $\mathrm{R}_{1}$ & $\mathrm{R}_{2}$ & $\mathrm{R}_{3}$ & $\mathrm{R}_{4}$ \\
\hline $\mathrm{e}_{1}$ & $\mathrm{G}_{1}^{(1)}$ & $<\mathrm{s}_{6},[0.7,0.8],[0.2,0.3]>$ & $<\mathrm{s}_{4},[0.6,0.7],[0.3,0.4]>$ & $<\mathrm{s}_{3},[0.7,0.8],[0.2,0.3]>$ & $<\mathrm{s}_{6},[0.6,0.7],[0.3,0.4]>$ \\
& $\mathrm{G}_{2}^{(1)}$ & $<\mathrm{s}_{5},[0.5,0.6],[0.3,0.4]>$ & $<\mathrm{s}_{6},[0.5,0.7],[0.3,0.4]>$ & $<\mathrm{s}_{4},[0.7,0.9],[0.1,0.2]>$ & $<\mathrm{s}_{7},[0.6,0.8],[0.2,0.3]>$ \\
& $\mathrm{G}_{3}^{(1)}$ & $<\mathrm{s}_{4},[0.6,0.7],[0.3,0.4]>$ & $<\mathrm{s}_{4},[0.5,0.6],[0.4,0.5]>$ & $<\mathrm{s}_{6},[0.6,0.7],[0.3,0.4]>$ & $<\mathrm{s}_{5},[0.5,0.7],[0.3,0.4]>$ \\
& $\mathrm{G}_{4}^{(1)}$ & $<\mathrm{s}_{7},[0.6,0.8],[0.2,0.3]>$ & $<\mathrm{s}_{5},[0.7,0.8],[0.2,0.3]>$ & $<\mathrm{s}_{6},[0.5,0.6],[0.4,0.5]>$ & $<\mathrm{s}_{5},[0.8,0.9],[0.1,0.2]>$ \\
$\mathrm{e}_{2}$ & $\mathrm{G}_{1}^{(1)}$ & $<\mathrm{s}_{7},[0.7,0.8],[0.2,0.3]>$ & $<\mathrm{s}_{5},[0.6,0.8],[0.2,0.3]>$ & $<\mathrm{s}_{5},[0.7,0.8],[0.2,0.3]>$ & $<\mathrm{s}_{5},[0.6,0.7],[0.3,0.4]>$ \\
& $\mathrm{G}_{2}^{(1)}$ & $<\mathrm{s}_{5},[0.4,0.6],[0.4,0.5]>$ & $<\mathrm{s}_{6},[0.8,0.9],[0.1,0.2]>$ & $<\mathrm{s}_{4},[0.8,0.9],[0.1,0.2]>$ & $<\mathrm{s}_{8},[0.6,0.8],[0.2,0.3]>$ \\
& $\mathrm{G}_{3}^{(1)}$ & $<\mathrm{s}_{4},[0.7,0.8],[0.2,0.3]>$ & $<\mathrm{s}_{4},[0.6,0.7],[0.3,0.4]>$ & $<\mathrm{s}_{6},[0.7,0.8],[0.1,0.3]$ & $<\mathrm{s}_{5},[0.5,0.7],[0.4,0.5]>$ \\
& $\mathrm{G}_{4}^{(1)}$ & $<\mathrm{s}_{7},[0.6,0.8],[0.2,0.3]>$ & $<\mathrm{s}_{5},[0.7,0.9],[0.1,0.2]>$ & $<\mathrm{s}_{6},[0.6,0.7],[0.2,0.4]>$ & $<\mathrm{s}_{4},[0.8,0.9],[0.1,0.2]>$ \\
& $\mathrm{G}_{1}^{(1)}$ & $<\mathrm{s}_{7},[0.7,0.8],[0.2,0.3]>$ & $<\mathrm{s}_{5},[0.8,0.9],[0.1,0.2]>$ & $<\mathrm{s}_{6},[0.7,0.8],[0.2,0.3]>$ & $<\mathrm{s}_{5},[0.6,0.7],[0.3,0.4]>$ \\
& $\mathrm{G}_{2}^{(1)}$ & $<\mathrm{s}_{5},[0.8,0.9],[0.1,0.2]>$ & $<\mathrm{s}_{6},[0.8,0.9],[0.1,0.2]>$ & $<\mathrm{s}_{7},[0.7,0.9],[0.1,0.2]>$ & $<\mathrm{s}_{7},[0.7,0.8],[0.2,0.3]>$ \\
& $\mathrm{G}_{3}^{(1)}$ & $<\mathrm{s}_{6},[0.7,0.8],[0.2,0.3]>$ & $<\mathrm{s}_{5},[0.6,0.8],[0.2,0.3]>$ & $<\mathrm{s}_{8},[0.5,0.7],[0.3,0.4]>$ & $<\mathrm{s}_{6},[0.5,0.7],[0.3,0.4]>$ \\
& $\mathrm{G}_{4}^{(1)}$ & $<\mathrm{s}_{7},[0.6,0.8],[0.2,0.3]>$ & $<\mathrm{s}_{5},[0.7,0.8],[0.2,0.3]>$ & $<\mathrm{s}_{6},[0.6,0.7],[0.3,0.4]>$ & $<\mathrm{s}_{7},[0.8,0.9],[0.1,0.2]>$ \\
& & & &
\end{tabular}

Table 3 The computation results of attribute distance between historical cases and the target case

\begin{tabular}{|c|c|c|c|c|c|}
\hline Historical cases & $\Delta\left(x_{01}^{(1)}, x_{j 1}\right)$ & $\Delta\left(x_{02}^{(1)}, x_{j 2}\right)$ & $\Delta\left(x_{03}^{(1)}, x_{j 3}\right)$ & $\Delta\left(x_{04}^{(1)}, x_{j 4}\right)$ & $\Delta\left(x_{04}^{(1)}, x_{j 4}\right)$ \\
\hline $\mathrm{c}_{1}$ & 0.4231 & 0.1374 & 0.3177 & 0.5000 & 0.2774 \\
\hline $\mathrm{c}_{2}$ & 0.3077 & 0.7071 & 0.8092 & 0.8660 & 1.0000 \\
\hline$c_{3}$ & 0.4615 & 0.0000 & 0.9923 & 0.8660 & 0.1961 \\
\hline $\mathrm{c}_{4}$ & 1.0000 & 0.0971 & 0.1562 & 0.0000 & 0.1961 \\
\hline$c_{5}$ & 0.0641 & 1.0000 & 0.9957 & 0.5000 & 0.1387 \\
\hline $\mathrm{c}_{6}$ & 0.4103 & 0.3071 & 0.1550 & 0.5000 & 0.5883 \\
\hline $\mathrm{c}_{7}$ & 0.2564 & 0.9713 & 1.0000 & 0.0000 & 0.3101 \\
\hline $\mathrm{c}_{8}$ & 0.3333 & 0.3885 & 0.5114 & 1.0000 & 0.3101 \\
\hline $\mathrm{c}_{9}$ & 0.1667 & 0.3071 & 0.6987 & 0.0000 & 0.1387 \\
\hline $\mathrm{c}_{10}$ & 0.8462 & 0.6219 & 0.2166 & 0.5000 & 0.3101 \\
\hline
\end{tabular}


Table 4 The results of group evaluation $p_{a l}^{(1)}$

\begin{tabular}{lllll}
\hline & $p_{a 1}^{(1)}$ & $p_{a 2}^{(1)}$ & $p_{a 3}^{(1)}$ & $p_{a 4}^{(1)}$ \\
\hline $\mathrm{G}_{1}^{(1)}$ & $<\mathrm{s}_{7},[0.7,0.8],[0.2,0.3]>$ & $<\mathrm{s}_{5},[0.7,0.8],[0.2,0.3]>$ & $<\mathrm{s}_{6},[0.7,0.8],[0.2,0.3]>$ & $<\mathrm{s}_{6},[0.6,0.7],[0.3,0.4]>$ \\
$\mathrm{G}_{2}^{(1)}$ & $<\mathrm{s}_{6},[0.6,0.8],[0.3,0.4]>$ & $<\mathrm{s}_{6},[0.7,0.9],[0.2,0.3]>$ & $<\mathrm{s}_{5},[0.7,0.9],[0.1,0.2]>$ & $<\mathrm{s}_{7},[0.6,0.8],[0.2,0.3]>$ \\
$\mathrm{G}_{3}^{(1)}$ & $<\mathrm{s}_{5},[0.7,0.8],[0.2,0.3]>$ & $<\mathrm{s}_{4},[0.6,0.7],[0.3,0.4]>$ & $<\mathrm{s}_{7},[0.6,0.7],[0.3,0.4]>$ & $<\mathrm{s}_{5},[0.5,0.7],[0.3,0.4]>$ \\
$\mathrm{G}_{4}^{(1)}$ & $<\mathrm{s}_{7},[0.6,0.8],[0.2,0.3]>$ & $<\mathrm{s}_{5},[0.7,0.8],[0.2,0.3]>$ & $<\mathrm{s}_{6},[0.6,0.7],[0.2,0.4]>$ & $<\mathrm{s}_{5},[0.8,0.9],[0.1,0.2]>$ \\
\hline
\end{tabular}

Table 5 Normalized interval-valued evaluation information

\begin{tabular}{lllll}
\hline & $\mathrm{R}_{1}$ & $\mathrm{R}_{2}$ & $\mathrm{R}_{3}$ & $\mathrm{R}_{4}$ \\
\hline $\mathrm{G}_{1}^{(1)}$ & {$[0.7279,0.8812]$} & {$[0.4947,0.6693]$} & {$[0.7037,1.0000]$} & {$[0.2144,0.2784]$} \\
$\mathrm{G}_{2}^{(1)}$ & {$[0.2912,0.5713]$} & {$[0.8029,1.0000]$} & {$[0.0000,0.5477]$} & {$[0.7467,1.0000]$} \\
$\mathrm{G}_{3}^{(1)}$ & {$[0.0000,0.0953]$} & {$[0.0000,0.1069]$} & {$[0.4942,0.8007]$} & {$[0.0000,0.1636]$} \\
$\mathrm{G}_{4}^{(1)}$ & {$[0.6299,1.0000]$} & {$[0.4301,0.6206]$} & {$[0.1959,0.3613]$} & {$[0.4963,0.6370]$} \\
\hline
\end{tabular}

Table 6 Perceived utility $Q_{a l}^{(1)}$

\begin{tabular}{lrrrr}
\hline & \multicolumn{1}{c}{$Q_{a 1}^{(1)}$} & \multicolumn{1}{c}{$Q_{a 2}^{(1)}$} & $Q_{a 3}^{(1)}$ & \multicolumn{1}{c}{$Q_{a 4}^{(1)}$} \\
\hline $\mathrm{G}_{1}^{(1)}$ & 0.8231 & 0.7247 & 0.8407 & 0.0344 \\
$\mathrm{G}_{2}^{(1)}$ & 0.3028 & 0.9235 & 0.5214 & 0.8873 \\
$\mathrm{G}_{3}^{(1)}$ & -0.1916 & -0.1867 & 0.8890 & -0.1552 \\
$\mathrm{G}_{4}^{(1)}$ & 0.8344 & 0.6258 & 0.6057 & 0.5186 \\
\hline
\end{tabular}

that need to be determined during the calculation process, and different parameters lead to different results. In regret theory, the reference point need not be determined, and fewer parameters are involved in the calculation process. In addition, CBR-GDMPT adopts the form of interval number to evaluate decision makers' opinion. The proposed method adopts the form of IVPFLV, which is a better representation of uncertainty.

4. The calculated result obtained using the method based on CBR-IVPFLVPT is $c_{4}>c_{1}>c_{9}>c_{6}$. The most suitable case is $c_{4}$, which is the same as that obtained using the proposed method. However, as discussed above, the computation process of the prospect theory is a little more complicated than the regret theory.

In addition, the proposed method considers the dynamic nature of an emergency and generates different alternatives according to changes in emergencies, whereas the other methods generate an alternative based on the situation when the emergency occurs. Emergencies constantly evolve and are often accompanied by secondary disasters. Therefore, by continuously modifying the emergency alternatives, we can better respond to emergencies.

\subsubsection{Advantages of the Proposed Approach}

From the comparison with the existing EDM methods, we summarize the following advantages of the proposed dynamic CBRGDM approach: (1) The existing EDM based on the CBR does not consider the evolution of the emergency, and the alternative generated is constant throughout the emergency process. The proposed method considers the changes in an emergency and generates an alternative according to these changes. It can therefore better respond to emergencies. (2) In the case selection, using IVPFLVs can better represent the fuzziness and uncertainty in the evaluation information given by decision makers. This is particularly useful for EDM problems characterized by time limitations, partial or incomplete information, and limited expertise. (3) With the regret theory, the proposed method can consider the psychological behaviors of decision makers under emergency situations. As a result, a more accurate ranking of the similar historical cases can be derived in the EDM. 
Table 7 Comparisons with different approaches

\begin{tabular}{lc}
\hline Approach & $\begin{array}{l}\text { The most } \\
\text { suitable case }\end{array}$ \\
\hline CBR-F (case-based reasoning proposed by Fan et al. 2014) & $c_{9}$ \\
CBR-IVPFLWA (case-based reasoning based on interval-valued Pythagorean fuzzy linguistic weighted averaging) & $c_{9}$ \\
CBR-GDMPT (case-based reasoning based on group decision making and prospect theory) & $c_{4}$ \\
$\begin{array}{l}\text { CBR-IVPFLVPT(case-based reasoning based on interval-valued Pythagorean fuzzy linguistic variable and prospect } \\
\text { theory) }\end{array}$ & $c_{4}$ \\
CBRGDM (case-based reasoning group decision making) & $c_{4}$ \\
\hline
\end{tabular}

\section{Conclusion}

To generate a suitable emergency alternative, this article proposed a dynamic EDM method based on CBR and GDM, called dynamic CBRGDM. Compared with existing EDM methods, the proposed method has the following three characteristics: (1) To quickly generate an emergency alternative, the CBR method is applied to generate a similar historical case set. The alternative of the target emergency is generated based on the similar historical case set. (2) GDM is used to select the most suitable and similar historical case. In this process, IVPFLVs are used to express any vague information. Furthermore, regret theory is applied to determine the most suitable historical case considering the bounded rationality of decision makers. (3) To better deal with emergencies, the proposed method adjusts the alternative according to the different stages of an emergency.

In the future, two following issues need to be addressed: (1) extension of the case retrieval method in the context of big data; (2) development of a new method for evaluation information. Further, in the EDM, in addition to the opinions of decision makers, public opinions also need to be considered. Considering the uncertainty of the emergency, public opinions will be expressed as uncertain using interval-valued Pythagorean fuzzy set, soft set, and other uncertain and fuzzy environments.

Acknowledgements This work was partly supported by the National Natural Science Foundation of China under the Grant Nos. 71371053 and 71902034; Humanities and Social Sciences Foundation of Chinese Ministry of Education, No. 20YJC630229; Humanities and Social Science Foundation of Fujian Province, No. FJ2019B079; and Science and Technology Development Center of Chinese Ministry of Education, No. 2018A01019.

Open Access This article is licensed under a Creative Commons Attribution 4.0 International License, which permits use, sharing, adaptation, distribution and reproduction in any medium or format, as long as you give appropriate credit to the original author(s) and the source, provide a link to the Creative Commons licence, and indicate if changes were made. The images or other third party material in this article are included in the article's Creative Commons licence, unless indicated otherwise in a credit line to the material. If material is not included in the article's Creative Commons licence and your intended use is not permitted by statutory regulation or exceeds the permitted use, you will need to obtain permission directly from the copyright holder. To view a copy of this licence, visit http://creativecommons. org/licenses/by/4.0/.

\section{References}

Bell, D.E. 1982. Regret in decision making under uncertainty. Operations Research 30(5): 961-981.

Biswas, S.K., M. Chakraborty, H.R. Singh, D. Devi, B. Purkayastha, and A.K. Das. 2017. Hybrid case-based reasoning system by cost-sensitive neural network for classification. Soft Computing 21(24): 7579-7596.

Chorus, C. 2012. Regret theory-based route choices and traffic equilibria. Transportmetrica 8(4): 291-305.

Ding, X.F., and H.C. Liu. 2019a. An extended prospect theoryVIKOR approach for emergency decision making with 2-dimension uncertain linguistic information. Soft Computing 23: $12139-12150$

Ding, X.F., and H.C. Liu. 2019b. A new approach for emergency decision making based on zero-sum game with Pythagorean fuzzy uncertain linguistic variables. International Journal of Intelligent Systems 34(7): 1667-1684.

Ding, X.F., H.C. Liu, and H. Shi. 2019. A dynamic approach for emergency decision making based on prospect theory with interval-valued Pythagorean fuzzy linguistic variables. Computers \& Industrial Engineering 131: 57-65.

Ding, X.F., L. Zhang, and H.C. Liu. 2020. Emergency decision making with extended axiomatic design approach under picture fuzzy environment. Expert Systems 37(2): 1-14.

Dou, R., D. Lin, G. Nan, and S. Lei. 2018. A method for product personalized design based on prospect theory improved with interval reference. Computers \& Industrial Engineering 125(11): 708-719.

Du, Y., F. Hou, W. Zafar, and Q. Yu. 2017. A novel method for multiattribute decision making with interval-valued Pythagorean fuzzy linguistic information. International Journal of Intelligent Systems 32: 1085-1112.

Fan, Z.P., Y.H. Li, X. Wang, and Y. Liu. 2014. Hybrid similarity measure for case retrieval in CBR and its application to emergency response towards gas explosion. Expert Systems with Application 41(5): 2526-2534.

Fan, Z.P., Y.H. Li, and Y. Zhang. 2015. Generating project risk response strategies based on CBR: A case study. Expert Systems with Application 42(6): 2870-2883.

Gao, J., Z.S. Xu, Z.L. Liang, and H.C. Liao. 2019. Expected consistency-based emergency decision making with incomplete 
probabilistic linguistic preference relations. Knowledge-Based Systems 176: 15-28.

Han, M., and Z.J. Cao. 2015. An improved case-based reasoning method and its application in endpoint prediction of basic oxygen furnace. Neurocomputing 149: 1245-1252.

Jiang, Y.P., Z.P. Fan, and J. Ma. 2008. A method for group decision making with multi-granularity linguistic assessment information. Information Sciences 178(4): 1098-1109.

Laciana, C.E., and E.U. Weber. 2008. Correcting expected utility for comparisons between alternative outcomes: A unified parameterization of regret and disappointment. Journal of Risk \& Uncertainty 36(1): 1-17.

Li, M.Y., and P.P. Cao. 2019. Extended TODIM method for multiattribute risk decision making problems in emergency response. Computers \& Industrial Engineering 135: 1286-1293.

Li, H., and J. Sun. 2009. Majority voting combination of multiple case-based reasoning for financial distress prediction. Expert Systems with Applications 36(3): 4363-4373.

Liao, Z., X. Mao, P.M. Hannam, and T. Zhao. 2012. Adaptation methodology of CBR for environmental emergency preparedness system based on an improved genetic algorithm. Expert Systems with Applications 39(8): 7029-7040.

Liu, H.C., M.Y. Quan, Y. Shi, and C. Guo. 2019. An integrated MCDM method for robot selection under interval-valued Pythagorean uncertain linguistic environment. International Journal of Intelligent Systems 34(2): 188-214.

Loomes, G., and R. Sugden. 1982. Regret theory: An alternative theory of rational choice under uncertainty. The Economic Journal 92(368): 805-824.

Park, C.S., and I. Han. 2002. A case-based reasoning with the feature weights derived by analytic hierarchy process for bankruptcy prediction. Expert Systems with Applications 23(3): 255-264.

Peng, X., and H. Garg. 2018. Algorithms for interval-valued fuzzy soft sets in emergency decision making based on WDBA and CODAS with new information measure. Computers \& Industrial Engineering 119: 439-452.

Peng, X., and Y. Yang. 2017. Algorithms for interval-valued fuzzy soft sets in stochastic multi-criteria decision making based on regret theory and prospect theory with combined weight. Applied Soft Computing 54: 415-430.

Quiggin, J. 1997. Regret theory with general choice sets. Journal of Risk and Uncertainty 8(2): 153-165.

Ren, P., Z. Xu, and Z. Hao. 2017. Hesitant fuzzy thermodynamic method for emergency decision making based on prospect theory. Cybernetics, IEEE Transactions on Learning Technologies 47(9): 2531-2543.

Wan, S.P., F.F. Yuan, and J.Y. Dong. 2017. Extended VIKOR method for multiple criteria decision-making with linguistic hesitant fuzzy information. Computers \& Industrial Engineering 112: 305-319.

Wang, L., and N. Li. 2020. Pythagorean fuzzy interaction power Bonferroni mean aggregation operators in multiple attribute decision making. International Journal of Intelligent Systems 35(1): 150-183.

Wang, L., R.M. Rodriguez, and Y.M. Wang. 2018. A dynamic multiattribute group emergency decision making method considering experts' hesitation. International Journal of Computational Intelligence Systems 11: 163-182.

Wang, L., Y.M. Wang, and M. Luis. 2017. A group decision method based on prospect theory for emergency situations. Information Sciences 418-419: 119-135.

Wang, L., Z.X. Zhang, and Y.M. Wang. 2015. A prospect theorybased interval dynamic reference point method for emergency decision making. Expert Systems with Applications 42(23): 9379-9388.

Wu, Q., W. Peng, L. Zhou, H. Chen, and X. Guan. 2018. Some new Hamacher aggregation operators under single-valued neutrosophic 2-tuple linguistic environment and their applications to multi-attribute group decision making. Computers \& Industrial Engineering 116: 144-162.

Xu, X., X. Yin, and X. Chen. 2019. A large-group emergency risk decision method based on data mining of public attribute preferences. Knowledge-Based Systems 163: 495-509.

Yan, A., H. Shao, and Z. Guo. 2014. Weight optimization for case based reasoning using membrane computing. Information Sciences 287: 109-120.

Yu, L., and K.K. Lai. 2011. A distance-based group decision-making methodology for multi-person multi-criteria emergency decision support. Decision Support Systems 51(2): 307-315.

Yu, F., X.Y. Li, and X.S. Han. 2018. Risk response for urban water supply network using case-based reasoning during a natural disaster. Safety Science 106: 121-139.

Zadeh, L.A. 1975. The concept of a linguistic variable and its application to approximate reasoning-I. Information Sciences 8(3): 199-249.

Zhang, Z.X., L. Wang, and Y.M. Wang. 2018. An emergency decision making method based on prospect theory for different emergency situations. International Journal of Disaster Risk Science 9(3): 407-420.

Zhang, S., J. Zhu, X. Liu, and Y. Chen. 2016. Regret theory-based group decision-making with multidimensional preference and incomplete weight information. Information Fusion 31: 1-13.

Zhao, K., and X. Yu. 2011. A case based reasoning approach on supplier selection in petroleum enterprises. Expert Systems with Applications 38(6): 6839-6847.

Zheng, J., Y.M. Wang, Y. Lin, and K. Zhang. 2019. Hybrid multiattribute case retrieval method based on intuitionistic fuzzy and evidence reasoning. Journal of Intelligent \& Fuzzy Systems 1: $1-12$.

Zheng, J., Y.M. Wang, and K. Zhang. 2018. A case retrieval method combined with similarity measurement and DEA model for alternative generation. International Journal of Computational Intelligence Systems 11(1): 11-23. 